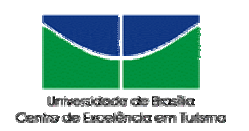

Universidade de Brasília Centro de Excelência em Turismo

\title{
FATORES LIMITANTES DA ATUAÇÃO DO BRASÍLIA CONVENTION \& VISITORS BUREAU NA CAPTAÇÃO DE EVENTOS DE GRANDE PORTE
}

\author{
Aluno: Juliana Lima de Regueiro
}

Orientadora: Leonor Moreira Câmara

\begin{abstract}
Monografia apresentada ao Centro de Excelência em Turismo da Universidade de Brasília como requisito parcial para a obtenção do certificado de Especialista em Gestão da Hospitalidade.
\end{abstract}

Brasília, DF, janeiro de 2004. 


\author{
UNIVERSIDADE DE BRASÍLIA \\ Centro de Excelência em Turismo \\ Curso de Especialização em Gestão da Hospitalidade
}

\title{
FATORES LIMITANTES DA ATUAÇÃO DO BRASÍLIA CONVENTION \& VISITORS BUREAU NA CAPTAÇÃO DE EVENTOS DE GRANDE PORTE
}

Aluna: Juliana Lima de Regueiro

Banca Examinadora

Leonor Moreira Câmara, Doutora

Orientador

Membro da Banca

Brasília, DF, janeiro de 2004. 
JULIANA LIMA DE REGUEIRO

\title{
FATORES LIMITANTES DA ATUAÇÃO DO BRASÍLIA CONVENTION \& VISITORS BUREAU NA CAPTAÇÃO DE EVENTOS DE GRANDE PORTE
}

\author{
Comissão Avaliadora \\ Professora Orientadora Leonor Moreira Câmara \\ Professor (a) \\ Professor (a)
}

Brasília, DF, janeiro de 2004. 
Este trabalho é dedicado à Maria Soares, a mãe mais amorosa possível, que concedeu sua ajuda em todos os momentos difíceis da minha vida. 
Agradeço à Professora Doutora Leonor Moreira Câmara, pela orientação tão imparcial, enquanto coordenadora do curso. 


\section{RESUMO}

Palavras-chave: eventos; dificuldades; Convention \& Visitors Bureau.

A atividade de eventos depende diretamente da infra-estrutura, cuja definição dependerá do tamanho do evento, e também da captação que os órgãos ou empresas responsáveis terão de fazer para que ele seja realizado e com sucesso.

Com este trabalho pretende-se apresentar o resultado da pesquisa feita sobre o panorama da atividade de eventos, tais como: conceitos, destacando a importância do cliente; classificação; tipologia; sua evolução histórica; suas principais característica; a profissionalização da atividade e as qualidades que o profissional de eventos deve apresentar. Pretende-se, ainda, associar estes resultados ao papel do Brasília Convention \& Visitors Bureau - BCVB, seu trabalho de captação de eventos para o Distrito Federal e as dificuldades que este enfrenta quando se trata do desenvolvimento da atividade, em nível de grande porte, destacando-se as soluções e perspectivas para a melhora da situação em que o estado se encontra. 


\section{ABSTRACT}

Key words: events; difficulties; Convention \& Visitors Bureau.

The activities of the events depends directly on the infra-structure, which focuses on the size of the event, and also its capture, which is done by the responsible enterprises and institutions to enable it and make the event a success.

The intention of this statement is to present the results of a research done on the panorama of the events activities, such as concepts, giving emphasis to the client's important role; classification; typology; its historical evolution; main characteristics; the professionalization of this activity and the characteristics the professional must have. Further, it is intended to associate these results with the role of the Brasília Convention \& Visitors Bureau in the capture of events in the Federal District and the difficulties that this institution faces, while dealing with the development of this activity, on great size levels, emphasizing the solutions for these problems and the perspectives of improvement for the present situation of the State. 


\section{SUMÁRIO}

Capítulos

Páginas

1 - INTRODUÇÃO

2 - CONCEITO, CLASSIFICAÇÃO E TIPOLOGIA DE EVENTOS 5

2.1 - Conceito 5

2.2 - Classificação 7

2.3 - Tipologia

4 - CARACTERÍSTICAS GERAIS DOS EVENTOS

5 - O PROFISSIONAL DE EVENTOS A ORGANIZAÇÃO DO SETOR 16

5.1 - O Profissional de eventos 16

5.2 - A organização do setor de eventos 17

6 - O CONVENTION \& VISITOS BUREAU E O PROCESSO DE CAPTAÇÃO DE EVENTOS 20

6.1 - O Processo de captação $\quad 22$

7 - OS ESPAÇOS PARA EVENTOS DE GRANDE PORTE 25

7.1 - Panorama dos espaços para eventos disponíveis em Brasília $\quad 27$

8 - COCLUSÃO

9 - BIBLIOGRAFIA 


\section{INTRODUÇÃO}

Este trabalho trata da atividade de eventos que é um tema de grande relevância pois representa além de uma grande parcela da atividade turística, um considerável movimento na economia das localidades em que se realizam, além de ser um potencial multiplicador turístico, ajuda na redução dos problemas de sazonalidade, pelo fato de a dinâmica deste mercado concentrar-se na baixa estação; cria uma imagem positiva das localidades-sede e mobiliza o trade turístico, movimentando a economia.

Em estágio realizado em uma empresa organizadora de eventos percebeu-se que diversos agentes econômicos se beneficiam com esta atividade, como é o caso dos prestadores de serviços como transportes, alimentação e comércio em geral, além de propiciar a geração de empregos diretos e indiretos; a profissionalização e a otimização da mão-de-obra; a criação de novas profissões; o aumento e a redistribuição da renda individual; a arrecadação de mais impostos, ocasionando o aumento da receita local e o ingresso de divisas no país, no caso de eventos internacionais.

Ansarah (2000: 75) afirma que sediar eventos também tem sido uma forma de os países promoverem a sua imagem, de se apresentarem ao mundo e de gerarem lucros para as localidades-sede, tendo em vista que o evento, em todas as suas fases, desde a concepção da idéia até a realização e o encerramento, representa um grande estímulo para a economia de qualquer localidade, pois envolve um grande número de agentes econômicos, o que dinamiza e encrementa as atividades econômicas.

Em seu folheto promocional, os organizadores da UBRAFE - Congresso Brasileiro de Promoção Comercial e Feira Internacional de Promoção Comercial colocam que as feiras e exposições internacionais são instrumentos de conquista de mercados externos e de expansão das exportações, atraindo expositores e compradores internacionais $O$ setor alavanca exportações, permitindo o acesso 
de pequenas e médias empresas ao mercado internacional. São também responsáveis por grande parte dos fluxos turísticos para uma infinidade de destinos.

Diz ainda que o Brasil dispõe de potencial para desenvolver este setor e pode dar resposta rápida aos investimentos feitos nesta área, porque conta com os elementos necessários que são: economia diversificada e em crescimento; mercado interno fortíssimo; atrativos turísticos de forte impacto nacional e internacional; facilidade de deslocamento e acesso; diversidade e qualidade de centros de eventos, pavilhões e destinos; organismos de promoção e turismo organizados; empresas de promoção comercial bem estruturadas.

Brasília, sendo a capital do país, recebe repasses da verba federal, os quais são, geralmente, muito limitados. Devido a esta situação, o Distrito Federal vem tentando desenvolver o setor de serviços em conseqüência do processo de inchamento que a cidade vem sofrendo e também devido à migração de pessoas de outros estados da federação, até porque recebe, freqüentemente, turistas de negócios, devido à sua função administrativa. Outro fator seria por abrigar servidores públicos federais que, em sua maioria, não possuem residência fixa na cidade. Mais um fator relevante seria que as pessoas estão buscando praticidade em suas vidas, pois a jornada de trabalho é quase sempre de oito horas e elas não dispõem de tempo suficiente para preparar uma refeição. Isso explica o fato de Brasília ser considerada o terceiro centro gastronômico do país.

Com esse crescimento acelerado faz-se necessária uma busca por alternativas de postos de trabalho, renda e arrecadação para a cidade. Com isso a área de eventos se mostra cada vez mais promissora, haja vista o fato de Brasília estar localizada no eixo central do Brasil e da América Latina.

Em entrevista realizada com Lilia Tanner (Brasília Covention \& Visitors Bureau), ela confirma que pelo motivo de Brasília ter uma localização privilegiada, muitos profissionais da área consideram que a cidade possui uma vocação natural para o desenvolvimento da atividade de eventos, pois centraliza o acesso dos participantes provenientes destas regiões. Por se tratar de uma cidade tombada 
como patrimônio cultural da humanidade, pela sua modernidade, e por ser a capital do país, pode vir a se tornar um atrativo para o turismo cívico, além de oferecer facilidades no que tange ao comparecimento de autoridades nos eventos, pois é o centro do poder, o que faz do evento algo prestigiado e de grande importância.

Ainda segundo Lília Tanner, a indústria hoteleira do Distrito Federal cresceu cerca de 34\% de 2000 a 2003 e futuros investimentos já estão programados, o que significa que a cidade já está se preparando para sediar os eventos que aqui acontecerão. A atividade de eventos é uma maneira de a hotelaria, que apresenta baixa ocupação devido ao grande número de hotéis existentes, se recuperar dos incontestáveis prejuízos que vem sofrendo.

Para que este fato seja consolidado, é necessário que o governo local em parceria com o governo federal e a iniciativa privada, invistam na construção de espaços para eventos de grande porte e na reforma do Centro de Convenções de Brasília, o que já está em andamento, além de uma participação mais ativa por parte dos contribuintes do Brasília Convention and Visitors Bureau, principalmente no que tange à área de promoção da cidade, para que haja um maior aproveitamento em divulgação da cidade como receptor de eventos e, assim, incrementar sua captação.

No trabalho são descritos alguns conceitos, as classificações e a tipologia dos eventos no ponto de vista de diferentes autores; a evolução histórica desta atividade, destacando-se as mudanças ocorridas; algumas de suas características mais relevantes; o profissional e a profissionalização da atividade; o Convention \& Visitors Bureau no processo de captação dos eventos, destacando seu papel e sua organização, fazendo uma ligação deste com a infra-estrutura existente em Brasília.

Com este trabalho pretende-se fazer um levantamento dos fatores que dificultam o trabalho do BCVB, tais como a infra-estrutura de espaços disponíveis para a atividade de eventos de grande porte no Distrito Federal, os recursos humanos e suas limitações, o amadorismo que o setor apresenta, a falta de interesse do 
poder público, o ponto de vista do Brasília Convention \& Visitors Bureau e suas perspectivas.

O objeto do estudo será uma análise dos diversos fatores que limitam a atuação do Brasília Convention \& Visitors Bureau na captação dos eventos que poderiam acontecer na cidade, mas que acabam sendo direcionados para outras.

A metodologia utilizada foi o uso de pesquisa bibliográfica em fontes secundárias através de leitura de documentos públicos, revistas, livros e artigos de diversos autores da área, além de pesquisa de campo com fontes primárias, na qual foi aplicada entrevista aberta, aparada em roteiro predefinido, com a Gerente de Captação de Recursos e Mantenedores do Brasília Convention \& Visitors Bureau, Lilia Tanner, realizada em 12 de setembro de 2003 e com o engenheiro Eduardo Borges, responsável pela reforma do Centro de Convenções Ulisses Guimarães, em 23 de agosto de 2003. Alguns dados foram retirados de pesquisas na Internet e observações que foram feitas a partir de experiências profissionais, tais como estágio na empresa organizadora de eventos, Consultrade; no Departamento de Eventos da EMBRATUR - Instituto Brasileiro de Turismo e dos serviços prestados como recepcionista em diversos eventos realizados em Brasília, através de empresas de eventos. 


\section{CONCEITO, CLASSIFICAÇÃO E TIPOLOGIA DE EVENTOS}

\subsection{Conceito}

Dentre as bibliografias consultadas, contendo conceitos de evento, o mais interessante seria citar os autores que se seguem, pois o critério de escolha foi feito de maneira que haja uma coincidência de opiniões de áreas diversas, já que a primeira autora se remete à área do turismo, enquanto que a segunda, à de Relações Públicas.

Segundo Canton (1998: 101), a palavra evento para um leigo sugere festa, enquanto que para um profissional de olho nas mudanças na economia de mercado, sugere um instrumento estratégico colocado à sua disposição.

Para essa autora, o significado da palavra evento é "todo fato ou acontecimento, espontâneo ou organizado, ocorrido na sociedade, que sob o ponto de vista profissional pressupõe planejamento e organização", ou ainda, "soma de ações, previamente planejadas, com o objetivo de alcançar resultados definidos, junto ao seu público-alvo".

Cesca (1997: 14), diz que para relações públicas, o evento é a execução de um projeto devidamente planejado de um acontecimento, com o objetivo de manter, elevar ou recuperar o conceito de uma organização junto ao seu público de interesse.

Diante dos conceitos mencionados, conclui-se que o público é o principal motivo de todo o processo de organização e execução de eventos e explicita a questão do planejamento inerente aos eventos, enquanto atividade organizada. 
Deve ser levado em consideração o grau de dificuldade da escolha da atividade de eventos como área de atuação, pois vários são os fatores que contribuem para a complexidade deste trabalho. Primeiramente, como lidar com recursos humanos, principalmente no que se refere ao amadorismo, que continua sendo inerente a esta profissão e também ao fato de, na maioria das vezes os atores deste processo terem níveis de instrução, educação e classe social diferenciados. Depois, os prazos a se cumprir, os quais muitas vezes são curtos; em seguida, a escolha da infra-estrutura a ser utilizada, que será determinada pelo tamanho do evento e, finalmente uma série de detalhes que se forem observados de maneira consciente farão a diferença para obter-se um evento de sucesso.

A Federação Brasileira dos Convention \& Visitors Bureau, em parceria com o SEBRAE Nacional, divulgaram em 2002, uma pesquisa por eles desenvolvida, entitulada "I Dimensionamento Econômico da Indústria de Eventos no Brasil", a qual era inédita neste segmento.

A pesquisa "compreende a identificação e a qualificação dos espaços de eventos, em termos de capacidade, equipamentos, serviços, níveis de ocupação, preços praticados e recursos humanos empregados. Compreende ainda, os gastos dos participantes dos eventos na localidade, assim como os gastos dos promoteres e organizadores dos eventos com fornecedores de bens e serviços. Os resultados são o volume de geração de renda, empregos e impostos.", conforme "site" da Federação Brasileira dos CVBs.

Consta ainda que foram feitas duas pesquisas com públicos diversos, porém complementares: espaços para a realização de eventos e as empresas organizadoras ou entidades promotoras. Foram aplicados questionários, na forma de entrevistas com os representantes das empresas em 120 cidades brasileiras. Também foram feitas entrevistas diretas, por telefone, "e-mail" ou fax, através de questionários fechados e codificados, com a aplicação de pré-teste também.

Constatou-se na pesquisa, que acontecem no país, mais de 327.000 eventos por ano, aos quais comparecem 80 milhões de participantes, que são potenciais consumidores dos produtos, equipamentos e serviços ofertados. 
Este setor movimenta 1780 centros de exposições e espaços para eventos em todo o país, respondendo por 3 milhões de empregos diretos, indiretos e temporários e mobiliza centenas de empresas organizadoras. Com receita anual superior a R $\$ 37$ bilhões, o setor recolhe tributos da ordem de R $\$ 4,2$ bilhões.

O índice de ocupação dos espaços estudados (em média 50\%), aliada a diversificada cadeia produtiva de eventos, aponta para uma possibilidade de crescimento para o setor, sem que sejam necessários altos investimentos em infra-estrutura.

O gasto médio dos turistas de eventos, é de $\mathrm{R} \$ 392,00$, entre os setores de hospedagem, alimentação e transporte. Os participantes residentes gastam, em função do evento, cerca de $\mathrm{R} \$ 50,00$. A renda gerada pelos visitantes pode ser aumentada por meio de um melhor aproveitamento de sua permanência, com a criação de programações sociais e de lazer, com atrativos diferenciados e com a estimulação da vinda de acompanhantes.

No Distrito Federal o número de ventos que ocorrem por ano, é de 8.395 e de participantes por evento é em média de 165. Já o total de participantes por ano é de 1.384.914, com um gasto per capta de $R \$ 325,27$. A arrecadação anual é de $R \$ 12.572 .475,47$, sendo que o total de tributos pago fica em $R \$ 127.569 .653,79$. Esse movimento gera 160.582 empregos diretos e indiretos.

\section{2 . Classificação}

Os eventos podem ser classificados de diversas maneiras, dependendo do fator que se leva em consideração. No caso deste trabalho são analisados apenas os que influenciam no resultado da pesquisa sobre o BCVB que são o porte, que faz parte do objeto do trabalho e a área de interesse, que é um dado genérico. 
Ana Lúcia Olegário Saraiva (2003), classifica os eventos, em relação ao tamanho, da seguinte maneira:

- Pequeno porte: até 200 participantes

- Médio porte: de 200 até 500 participantes

- Grande porte: a partir de 500 participantes

Quanto à questão financeira do processo associada ao porte do evento, constatase que os eventos de grande porte apresentam uma maior lucratividade e menor custo e trabalho, não só para o organizador, mas também para o próprio estado, motivo pelo qual este porte se tornou o objeto do trabalho, informação obtida a partir da entrevista com Lilia Tanner (BCVC) em 12 de setembro de 2003.

Em relação à área de interesse, Matias (2001: 62) classifica os eventos em:

- Artístico: relacionado a qualquer manifestação de arte

- Científico: Refere-se às ciências naturais e biológicas

- Cultural: Ressalta os aspectos de determinada cultura, para conhecimento geral ou promocional.

- Cívico: Assuntos ligados à pátria

- Desportivo: Ligado a esportes, independentemente da modalidade

- Folclórico: Manifestação de culturas regionais de um país

- Lazer: Proporciona entretenimento

- Promocional: Promove um produto, pessoa, entidade ou governo

- Religioso: Trata de assuntos religiosos, independentemente do credo

- Turístico: Explora os recursos turísticos de uma região ou país

Dentre os eventos que acontecem na cidade, os científicos, principalmente da área médica, são os que ocorrem com maior freqüência e, normalmente, são os de maior porte ocupando, também, o posto de mais lucrativos, destaca Tanner (BCVB). 


\subsection{Tipologia}

A tipologia é definida de acordo com o tipo de evento que se pretende fazer e como ele deve ser realizado, pois cada evento pressupõe um objetivo diferente, que deve adequar-se ao tipo de encontro.

Segundo Cesca (1997: 15), os tipos de eventos são:

- Programa de visitas: Consiste na aproximação entre o público e a empresa. A empresa recebe grupos de pessoas com o objetivo de divulgá-la por meio da apresentação de sua área física, fisiologia, política e ramo de atividade.

- Concursos: São competições que estimulam o interesse do público participante e a familiariza como empresa.

- Exposição: Visa apenas divulgar. O expositor adquire o espaço físico (estande) e participa com ou sem outros expositores.

- Feira: Visa vender. O expositor compra o espaço físico e participa juntamente com os outros.

- Salão: Visa divulgar, mas também apresenta características da feira. O procedimento é o mesmo.

- Mostra: Visa divulgar. Ela circula em vários locais com a mesma forma e conteúdo.

- Conferência: Exposição de um assunto de amplo conhecimento do conferencista, que é reconhecidamente competente.

- Palestra: O assunto é geralmente de natureza educativa e os ouvintes já possuem algum conhecimento sobre o assunto.

- Simpósio: Consiste em vários expositores, com a presença de um coordenador. O tema e geralmente científico é o objetivo é realizar um intercâmbio de informações.

- Painel: Há debate entre os expositores, sendo coordenado por um moderador.

- Mesa-redonda: Os expositores têm um tempo limitado para a exposição e posterior debate, sob a coordenação de um moderador.

- Convenção: possui vários expositores com a presença de um coordenador. 
- Congresso: Vários dias, geralmente com a coexistência de outros tipos dentro deste.

- Seminário: Igual à convenção, mas divide-se em três fases, que são exposição, discussão e conclusão. As decisões podem ser adotadas pela área ou não.

- Fórum: Caracteriza-se pela discussão e debate. Ao fim o coordenador colhe as opiniões e apresenta uma conclusão.

- Debate: é a discussão entre pessoas que defendem pontos de vistas sobre um tema.

- Brainstorming: Possui uma fase criativa e outra avaliativa, nas quais as pessoas apresentam idéias acerca de um problema.

- Conclave: é de caráter religioso e de ordem ética e moral. Os expositores são religiosos.

- Semana: Semelhante ao congresso.

- Entrevista coletiva: O expositor faz uma rápida explanação e é questionado por representantes da imprensa.

- Jornada: É de âmbito regional. Discute periodicamente assuntos de interesse do grupo.

- Workshop: Há a exposição e demonstração do objeto que gerou o evento, Normalmente é da área comercial ou empresarial.

- Oficina: semelhante ao workshop, mas é mais para a área educacional.

- Colóquio: Reunião fechada que objetiva esclarecer e tomar decisões, sob coordenação. 


\section{3 . A EVOLUÇÃO HISTÓRICA DA ATIVIDADE DE EVENTOS}

De acordo com Matias (2001: 1), a origem da atividade de eventos está nos primeiros jogos das Olimpíadas da Era Antiga, datados de 776 a.C., na cidade de Olímpia, na Grécia. O primeiro congresso de que se tem notícia ocorreu em Corinto, onde se reuniram os delegados das cidades gregas para eleger Felipe, o Generalíssimo da Grécia, nas lutas contra a Pérsia. Estes e outros eventos precursores deixaram várias contribuições para a atividade de eventos praticada atualmente, dentre as quais o espírito de hospitalidade, a infra-estrutura de acesso e os primeiros espaços para eventos. A Idade Média foi marcada por uma série de eventos religiosos, já que o poder estava sob controle da Igreja e do comércio. Passada a Idade Média, os indivíduos incorporaram o espírito investigativo e outras pessoas também começaram a viajar, como artistas, artesãos, músicos, e poetas, para mostrar seu trabalho, adquirir experiência profissional e conhecer outras localidades.

Segundo Tonatiuh (1991: 15), os eventos passaram a ser uma atividade profissionalmente organizada quando, no século XIX, o inglês Thomas Cook organizou a ida de um grupo de 540 pessoas para participar de um congresso, fretando um trem, com tarifas reduzidas, o qual iria de Leicester a Longborough, Inglaterra, lançando também o cupom de hotel, que hoje é conhecido como voucher. Esse conjunto caracterizou o primeiro pacote turístico. Logo depois fundou a empresa Thomas Cook and Sons, que atualmente se chama Wagon Lit's Cook, uma das organizações turísticas que mais movimentam em todo o mundo.

Ainda segundo Matias (2001: 4), com a Revolução Industrial as feiras receberam um grande impulso. Elas se tornaram verdadeiras organizações comerciais planejadas. Isso fazia com que as pessoas se motivassem ainda mais a viajar. Essa motivação também passou a se dar por interesses profissionais.

Novos espaços destinados às feiras foram construídos ou adaptados. O primeiro deles foi o Society of Arts, criado em 1754 a fim de estimular as artes e a 
indústria, sendo que o primeiro pavilhão de feiras e exposições foi o Palácio de Cristal, na Inglaterra, construído em 1851, com o uso de novas tecnologias e materiais, tais como vidro, ferro, aço e concreto armado, em uma estrutura gigantesca. Thomas Cook foi o responsável pela organização da viagem que levou 165 mil pessoas para assistir o evento inaugural. Isso foi o casamento ideal para que este desse certo e para os eventos seguintes também. Em 1936 este espaço foi destruído por um incêndio, após ser transferido de Hyde Park para Sydenham, acrescenta Marlene (2001)

A autora completa ainda que, o primeiro evento de que se tem conhecimento no Brasil, foi um baile de carnaval em 7 de fevereiro de 1840, no Hotel Itália. Em 1908, no Pavilhão de Feiras da Praia Vermelha, Rio de Janeiro, ocorreu a primeira feira nos moldes atuais, foi a Exposição Nacional. Este foi o primeiro local construído para receber grandes feiras. O evento mais reconhecidamente importante foi a Exposição Internacional do Centenário, realizado no Palácio das Festas, no Rio de Janeiro, em 1922, que comemorava o Centenário da Independência do Brasil. Este contou com a participação de 14 países, com 15 pavilhões construídos e recebeu 3.626.402 visitantes.

Quando fala-se em evento como atividade lucrativa, Matias (2001) destaca os eventos esportivos, pois normalmente são de grande porte. Os de maior importância são as Olimpíadas, que foram revitalizadas pelo Barão de Coubertin, em Atenas, surgindo a versão dos Jogos Olímpicos da Era Moderna. Outro, de grande Importância, é a Copa do Mundo, que surgiu em 1930, sendo que a primeira foi no Uruguai e que até hoje vem contribuindo para o desenvolvimento da atividade de eventos. A famosa corrida de carros Formula 1, que é caracterizada por sua mobilidade, atrai milhares de turistas de diversas nacionalidades para as localidades onde o evento se dá.

Em 1950, o Brasil foi sede da Copa do Mundo e para isso construiu o Estádio Mário Filho, também conhecido como Maracanã, em que hoje, além de jogos esportivos, também são promovidos shows com atrações nacionais e internacionais. 
Ansarah (2000: 76) diz que um grande meio de se obter lucratividade e que se torna uma forte tendência para o Brasil é a exploração de grandes eventos esportivos como a Copa do Mundo de Futebol, as Olimpíadas, os Jogos Panamericanos, Fórmula 1 entre outros, que trazem, além de todos os atletas, um grande número de turistas aficionados por estes esportes. Essa exploração também pode ser feita através de transmissão televisiva, com o grande negócio dos patrocínios e ainda por canais que se especializam neste filão. 


\section{CARACTERÍSTICAS GERAIS DOS EVENTOS}

As definições de Canton (1998) e de Cesca (1997), são técnicas e devem incorporar elementos que ampliam especificidades, por isso há necessidade de citar Matias (2001: 137) quando diz que os eventos são uma atividade econômica e social que surgiu praticamente com o advento da civilização humana e que caminha paralelamente a ela, adquirindo características representativas de cada período da história, até chegar à forma como se encontra atualmente, podendo variar de acordo com a cultura da população local e vem se modificando com o passar dos anos.

Outra característica destacada por Matias (2001) é que a organização de eventos vem apresentando crescimento constante em todo o mundo, tornando-se uma importante fonte econômica e geradora de benefícios sociais. Ela representa uma relação custo/benefício reconhecidamente vantajosa, além do grande proveito que traz para a relação da empresa com os clientes, fornecedores, mídia e público em geral.

Mais uma característica dos eventos que ocorrem no Brasil é que eles têm uma duração em média de cinco dias, e se concentram principalmente nos meses de maio a outubro, com pico em setembro, podendo ser nos planos local, estatal, regional, nacional, continental ou internacional, de acordo com Ansarah (2000: 77)

Do ponto de vista mercadológico, Canton (1998: 112) mostra que os eventos possuem pontos positivos que são a aproximação do produto com a empresa e a marca; associação da marca ao evento; ampliação do nível de conhecimento da marca e o fato de abranger um maior público direcionado. Já os pontos negativos são a necessidade de outros meios de "marketing" como reforço; de haver continuidade para surtir o efeito desejado; os riscos de ocorrências negativas que possam ser associadas à marca e erros na divulgação do evento. 
A autora diz ainda que os eventos caracterizam-se também por contribuir com a localidade-sede não somente financeiramente, mas também com 0 desenvolvimento dos grupos e empresas envolvidos com o tema do evento, possibilitando a melhoria das tecnologias e a difusão do conhecimento em áreas como a medicina, meio ambiente, educação, esportes, dentre outros.

Através do estágio na empresa de eventos constatou-se que os serviços geralmente contratados são agências de recepcionistas, agências de viagens, empresas de transportes, floricultura, aluguel de móveis e equipamentos de escritório, empresas de segurança, fotógrafos, serviços gerais (limpeza), buffets e os locais para eventos.

Os três fatores mais importantes a serem discutidos, com relação à dificuldade do desempenho do BCVB, na captação de eventos para Brasília, são a Gestão de pessoas, que será apresentado no capítulo seguinte, sobre o profissional de eventos,; o CVB ( cap. 06), que é órgão de maior responsabilidade na captação de eventos e a infra-estrutura (cap. 07), pois possui total influencia nas características dos eventos. 


\section{O PROFISSIONAL DE EVENTOS E A ORGANIZAÇÃO DO SETOR}

\section{1 - O profissional de eventos}

O organizador profissional de eventos é a pessoa que é responsável pela organização e pelo planejamento do evento. Ele é responsável por todo o andamento do processo, ficando a seu cargo o controle e acompanhamento de cada etapa, pois geralmente ele possui uma equipe que o ajudará a por em prática o trabalho planejado. Canton (1998) diz que a equipe de apoio deve ser coesa e eficiente, pois cada fase pertinente ao evento vai depender da sincronia em que os acontecimentos e a execução das ações vão acontecendo e grande parte delas é executada pela equipe e não pelo próprio organizador.

Seja qual for o tamanho do evento, o propósito não será alcançado se não houver alguém competente para se encarregar do planejamento, programação e conduta do evento, trata-se do organizador profissional de congressos. A ele não podem faltar certas atitudes e qualidades, o que não quer dizer que todos as possuam. São elas:

De acordo com Canton (1998: 102), não pode faltar conhecimentos técnicos, administrativos, de "marketing" e de economia. Ele deve exercitar continuamente sua criatividade e inteligência para a elaboração das propostas e estratégias de comunicação e "marketing". Também deverá ter uma visão técnica sobre a sua organização e uma visão global sobre o momento de sua atuação. A habilidade de perceber com detalhes todos os elementos econômicos, políticos, sociais e de qualquer outra natureza, que possam intervir na realização do evento, deve ser uma das mais marcantes características deste profissional.

Completa ainda, que ele deve ser seguro para gerar um clima de confiança ao cliente e à sua equipe; deve ser disciplinado, respeitando prazos, horários, verbas 
e reuniões; ser flexível, aceitando sugestões, adequando propostas, e fazendo mudanças na hora certa; deve ter raciocínio rápido, para captar as expectativas e anseios dos clientes e da equipe; estar saudável e bem preparado fisicamente; ser paciente e realista; ter autocontrole e seriedade,

Nichols (1993), já disse que através de treinamentos, experiência e sua própria educação contínua, esses profissionais têm desenvolvido habilidades e conhecimentos que os tornam aptos a juntar todos os complexos fatores envolvidos no planejamento e realização de um evento. Para isso é necessário o uso de sistemas, ferramentas e habilidades, mas que dependem também do talento do profissional.

Segundo Buendía (1991: 18), na Europa continental que é onde se realiza o maior número de eventos, surgiu um novo profissional: o organizador profissional de congressos $(\mathrm{PCO})$ e, consequentemente sua associação: Associação Internacional de Organizadores Profissionais de Congressos (IAPCO).

\section{2 - A organização do setor de eventos}

De acordo com Matias (2001: 26), o processo evolutivo da atividade de eventos provocou a organização do setor, surgindo entidades e associações especializadas neste setor e que são imbuídas de auxiliar na organização e execução de eventos nacionais e internacionais.

A autora complementa que o reconhecimento dos profissionais envolvidos no setor de eventos e da relevância da atividade no mercado e seu impacto na economia local, resultou no surgimento de entidades organizacionais tais como o CVB - Convention \& Visitors Bureau - com o propósito de promover a cidade em que se localizam e expandir seus negócios, principalmente na área de eventos, sendo que o primeiro Convention \& Visitors Bureau do Brasil é o da cidade de 
São Paulo e sua fundação data de 1983, o qual será melhor detalhado no próximo capítulo.

Conforme Matias (2001), quanto mais o segmento de eventos crescia, sua organização tornou-se motivo de preocupação, surgindo, então, a UFI - União de Feiras Internacionais - que era responsável pelo calendário e coordenação das feiras internacionais, pela criação facilidades aduaneiras e de transporte, e ainda, proporcionar ajuda técnica a elas.

O Convention Liasion Council, centralizador das informações relativas a indústria de encontros, convenções e exposições, foi fundado em 1949. Já em 1958, para dar sustentação e organização ao desenvolvimento do segmento, surge a AIPC Association Internacionale des Palais de Congres - com sede em Cannes, é o facilitador no intercâmbio de informações e experiências entre as organizações e afins. Ainda neste ano, foi formada a PCMA - Professional Convention Management Association, que tem sua excelência em educação reconhecida mundialmente. Em 1961 foi criada a ICCA - International Congress and Covention Association - com sede em Amsterdã, com intuito de contribuir legalmente para o desenvolvimento da atividade, Matias (2001).

No Brasil, ainda segundo a mesma autora, o mercado de eventos nasceu nos anos 50, com o lançamento da FENIT - Feira Nacional da Indústria Têxtil, que foi realizada em 1958, com a participação de 97 expositores. Hoje, algumas das principais feiras do Brasil são: o Salão do Automóvel, a Feira de Utilidades Domésticas e o Salão da Criança, sendo que a primeira empresa brasileira especializada na organização de eventos foi a Alcântara Machado Feiras e Promoções Ltda., que surgiu em 1967, em São Paulo e continua até os dias atuais.

A ABEOC - Associação Brasileira de Empresas de Eventos - cuja meta é coordenar, orientar e defender os interesses de seus associados, representados por empresas organizadoras, promotoras e prestadoras de serviços para eventos foi fundada em 15 de janeiro de 1977. A entidade está presente em quase todo o território nacional e possui ligações com organismos internacionais. É uma 
entidade civil, sem fins lucrativos nem caráter político-partidário e com jurisdição em todo o território nacional. Como entidade associativa, ela tem por objetivo congregar as empresas de serviços especializados em eventos, promover e incentivar as relações entre suas associadas no sentido de possibilitar intercâmbio técnico e cultural. É função da entidade também, a defesa dos interesses das associadas, tornando conhecidas, valorizadas e respeitadas as atividades profissionais do segmento. Matias (2001) explica que dentro destes objetivos ela promove:

- Reuniões periódicas com suas associadas

- Debates e palestras sobre assuntos de interesse do segmento de turismo e de eventos

- Congresso e Exposição Anual - EXCON

- Intercâmbio com empresários e associações de classe

- Divulgação da profissão de organizador, promotor e prestador de serviços para eventos

- Orientação de interessados na contratação de profissionais para eventos

- Estímulo à observância de um elevado sentido ético nas relações entre as associadas e entre essas e o mercado.

Em 1985 surge a ABRACCEF - Associação Brasileira de Centros de Convenções, Exposições e Feiras, que tem por finalidade o desenvolvimento institucional de seus associados e promover a integração e troca de experiências, além de orientar tecnicamente a implantação, construção e reformas de centros de convenções, (Matias 2001) 


\section{6 . O CONVENTION \& VISITORS BUREAU E O PROCESSO DE CAPTAÇÃO DE EVENTOS}

Segundo Nichols (1993: 21), os Convention \& Visitors Bureaus são organizações baseadas no sistema de filiação. Seus recursos provêm do setor privado, na forma de mensalidade cobrada dos filiados. Por este motivo, eles representam seus associados de forma igualitária.

Nichols (1993) diz que os CVBs existem nas localidades onde as convenções e o turismo são vitais para a economia local. A maioria deles funciona como organizações independentes, outros são departamentos ou divisões das Câmaras de Comércio, mas em alguns casos eles operam como um departamento do governo municipal. São estabelecidos como uma organização sem fins lucrativos, que representam a comunidade na captação e oferta de serviços. Eles reúne os interesses do governo local, dos associados e da indústria turística. Funcionam como ligação entre os possíveis visitantes e as empresas locais, tendo ainda, a função de agência de informações, consultor de eventos e turismo e agente promocional.

A autora complementa que para se obter informações sobre a cidade que se tem como candidata, há que se fazer uma pesquisa sobre todos os locais destinados para eventos e entrar em contato com todos eles, concluindo-se, assim, uma das etapas do planejamento do evento. Para que o organizador seja poupado deste e de outros trabalhos, ele deve consultar e contatar o CVB - Convention \& Visitors Bureau. É ele que pode esclarecer questões sobre clima, locais para eventos, fornecedores, hospedagem entre outros.

Nichols (1993) completa que os serviços do CVB não se resumem a informações. Apesar de variar de um para outro, alguns fazem um serviço de acompanhamento do evento, fornecimento de material impresso, emissão de correspondência, assistência publicitária em geral, favorecem encontros com autoridades etc., 
sendo que alguns destes serviços podem ser cobrados, haja vista o alto custo do serviço para o bureau.

O tamanho da equipe pode variar de dois funcionários até centenas em escritórios no mundo inteiro. Podem representar apenas uma cidade ou até suas adjacências, podendo variar também a sua capacidade de receptividade e funções executadas (Nichols 1993).

No "site" da Federação Brasileira dos CVBs, visitado em 20 de novembro de 2003, consta que para coordenar o conjunto dos Convention Bureaus, existe a IACVB - International Association of Convention \& Vistors Bureaus - a qual possui um quadro de mais de 1000 bureaus em países diferentes. Ela é reconhecida mundialmente e seu principal objetivo é a troca de experiências profissionais em eventos. Oferece, ainda, aos seus associados um Fórum para intercâmbio de idéias, assim como um extenso programa educacional.

Em nível nacional, existe a Federação Brasileira de Convention \& Visitors Bureaus. "Ela é constituída pelas entidades que atuam como CVBs no território brasileiro e tem por finalidade promover e representar suas associadas em todo e qualquer pleito de interesse do segmento por elas integrado e, especialmente, promover e cultivar o inter-relacionamento e intercâmbio de experiências e informações; diligenciar junto aos poderes públicos, apresentando-lhes alternativas e auxiliando na tomada de decisões que visem ao fomento da atividade de eventos; contribuir para o aperfeiçoamento das entidade associadas, visando a qualificação de suas atividades; exercer de modo geral, as atribuições que, por lei e pelos usos e costumes do país, sejam reservados às associações civis.", segundo consta em seu "site".

A Federação Brasileira foi fundada em 24 de abril de 1999, com 45 CVBs em todo o Brasil, agrupando em sua volta. A sede / foro está localizada em Brasília, a sede operacional é em Porto Alegre. 
O Brasília Convention \& Visitors Bureau - BCVB, é uma fundação de caráter privado, sem fins lucrativos, que foi fundada no dia 6 de outubro de 1995. Seus mantenedores são restaurantes, shopping centers, agências de viagens, montadoras de eventos, organizadoras de eventos, hotéis, entre outros, que perfazem um total de 83 contribuintes e uma arrecadação de R\$ 40.000 por mês, a qual é feita através da cobrança da "room tax" no valor de R\$1,50 de cada hóspede por diária nos hotéis, enquanto que os outros associados pagam $\mathrm{R} \$ 100$ mensalmente. Também recebe suporte por parte das instituições legais de cada segmento (ABAV - Associação Brasileira de Agências de Viagens, EMBRATUR, ABIH - Associação Brasileira da Indústria Hoteleira, Sindhobar - Sindicato de Hotéis e Bares etc.), segundo consta em seu folheto promocional.

Consta ainda que o montante arrecadado é investido na divulgação de Brasília como destino turístico, através de material promocional do tipo folhetos; cartazes; brindes; dossiê de captação; show case e o book. São investidos também em viagens de captação, incluindo todos os gastos para tal e em famtur, que consiste em uma viagem oferecida gratuitamente aos organizadores, de familiarização com a cidade candidata, entre outros.

\section{1 - O processo de captação de eventos}

Conforme Nichols (1993), o sistema de captação de eventos funciona da seguinte maneira: depois da divulgação do evento, os organizadores recebem informações de vários bureaus, através de cartas, ligações telefônicas, etc. explicando como a cidade pode satisfazer o plano do evento. Depois ocorre a inspeção do local e que fornecerá informações atuais sobre o local, através de visitas programadas, em companhia do executivo do CVB local, o que será mais detalhado no decorrer do capítulo. 
O processo de captação de eventos compõe um conjunto de ações, que divide-se em três etapas interligadas: preparação da captação, captação e pós-captação. Este processo caracteriza o evento como um produto e a captação como uma concorrência, demonstrando mais uma vez o grau de economicidade embutido nesta atividade.

$\mathrm{Na}$ fase de pré captação de eventos internacionais, o Convention \& Visitors Buraeu faz o contato com as fontes, tais como ICCA - International Congress and Convention Association - e IACVB - International association of Conventions \& Visitors Bureaus - para fazer um levantamento dos eventos que se realizam, sua periodicidade e etc.. Após essa pesquisa, o Convention \& Visitors Bureau faz uma seleção dos eventos que interessam para a sua região. Caso haja interesse, começa a fase da captação em que inicia-se o processo de preparação da candidatura desta localidade para sediar o evento. O Convention and Visitors Bureau fornecerá a documentação adequada, juntamente com o governo local, representado pela Secretaria de Turismo ou outro órgão competente e, ás vezes, até a iniciativa privada se associa a eles. Será elaborado um book, que geralmente é em inglês e de grande qualidade, com informações precisas e completas de acordo com a IACVB.

O book deverá conter:

- Cartas de apoio de autoridades:

- Governo do estado

- Prefeito do município-sede

- Ministério correspondente

- Ministério das Relações Exteriores

- Instituições ligadas ao turismo

- Convention \& Visitors Bureau

- Outras entidades de classe

- Sociedades científicas nacionais e latino-americanas

- Clareza e objetividade nos dados sobre a cidade, no que se refere a infraestrutura turística:

- Capacidade hoteleira

- Centros de Convenções 
- Estrutura aeroportuária

- Infra-estrutura de serviços

- Câmbio

- Vistos de entrada

- Transporte aéreo e urbano, etc.

- Justificativa do interesse da cidade ou país no evento, mostrando a importância científica, intercâmbio científico ou técnico e o potencial da cidade/país na especialidade do evento.

- Orçamento com previsão de gastos, contendo receitas e despesas e demonstrando a viabilidade econômica do projeto.

- Sugestão do local mais apropriado para o evento, apresentando suas instalações, serviços e demais informações.

- Folhetos sobre a cidade.

- Vídeo promocional.

- Catálogo e fotos dos locais disponíveis para o evento.

No caso de eventos nacionais, diz Nichols (2003), também são feitas pesquisas, sendo que serão sobre eventos nacionais, em companhias aéreas, na ABRACCEF - Associação Brasileira de Centros de Convenções, Exposições e Feiras, em calendários de eventos oficiais da EMBRATUR e etc. As associações e organismos oficiais procuram o Convention and Visitors Bureau, que por sua vez orienta e oferece todo o apoio técnico necessário.

Normalmente, a captação de eventos internacionais ocorre com antecedência mínima de três anos. Quando é pan-americano ou latino-americano, a antecedência é um pouco menor. Os nacionais exigem menos tempo, mas que pode variar de meses a dois anos.

$\mathrm{Na}$ fase da pós-captação, se for o caso, os prestadores de serviços que se propuseram a ajudar são comunicados do êxito, para, então iniciar-se o processo de organização do evento. Ocorre a contratação da empresa local organizadora de eventos, que poderá ser feita através de licitação e/ou concorrência, se a mesma já não estiver selecionada pelo proprietário do evento. 


\section{7 . ESPAÇOS PARA EVENTOS DE GRANDE PORTE}

Na pesquisa "I Dimensionamento Econômico da Indústria de Eventos no Brasil", publicada no "site" do BCVB, constatou-se que os espaços para eventos no Brasil são utilizados da seguinte maneira: $45 \%$ são realizados em hotéis/flats, $27 \%$ em teatros/auditórios, $5 \%$ em centros de convenções e $23 \%$ em outros, os quais serão mostrados em seguida.

De acordo com o estágio, constatou-se que escolha do espaço para eventos dependerá de vários fatores que influenciarão na decisão final, tais como quantidade de pessoas previstas para o evento, para que esteja de acordo com a capacidade do local; o tipo do evento; se o local comporta mais de uma modalidade de eventos; o público-alvo; os recursos financeiros disponíveis; o período em que ocorrerá, pois dependerá da disponibilidade do espaço; sua localização, para facilitar o acesso dos participantes, entre outros.

De acordo com as experiências profissionais na área de eventos, constatou-se que os principais tipos de espaços para eventos são:

\section{- PAVILHÕES DE EXPOSIÇÃO}

Os pavilhões de exposições tanto servem para este fim, quanto para eventos como "shows", feiras, salões entre outros. Estes locais podem sofrer mudanças temporárias para se adaptarem a certos tipos de eventos, como ser subdivididos, instalação de estandes, colocação de palco, etc..

\section{- CENTROS DE CONVENÇÕES}

Geralmente os Centros de Convenções possuem vários ambientes que fazem com que os grandes eventos se adeqüem melhor quando neles realizados. Quando o evento é grande e possui categorias diferenciadas de eventos, o centro de convenções se torna o local mais apropriado para o organizador. Este tipo de infra-estrutura também pode abrigar eventos de diferentes propósitos e organizadores, ao mesmo tempo. 


\section{- HOTÉIS}

Os hotéis possuem uma excelente infra-estrutura para eventos, pois dispõem de diferentes ambientes e muitas vezes, facilitam o trabalho da empresa organizadora, a partir do momento que disponibilizam os outros serviços, a custos reduzidos. Neste caso o evento pode ser totalmente realizado nas dependências do próprio hotel, o qual normalmente é o meio de hospedagem dos participantes. A maioria dos hotéis oferece um espaço relativamente pequeno para eventos, haja vista o propósito de sua construção, pois objetiva a hospedagem, devendo os eventos ser de pequeno ou médio porte e para um número limitado de pessoas. Já os hotéis de eventos, que são construídos também para eventos, oferecem uma melhor estrutura para que grandes eventos possam ser realizados confortavelmente.

A tendência da modernidade consiste em equipar os novos hotéis com salões para conferências e reuniões, espaços para exposições e auditórios, dotados de meios e equipamentos necessários para a realização de eventos cada vez mais bem estruturados.

\section{- UNIVERSIDADES}

As universidades são palco para diversos eventos, pois possuem grande quantidade de pessoas envolvidas, alunos, funcionários, dirigentes, e que normalmente são consideradas pessoas de muita importância para a sociedade em que vivem. No exterior é um dos locais mais utilizados para se realizarem eventos, não só da própria universidade, mas também de diversas outras instituições.

\section{- CLUBES}

Geralmente, os eventos que ocorrem nos clubes são festas em comemoração ao Ano Novo, casamentos, baile de debutantes e "shows", para um público selecionado, o qual em sua maioria não tem a finalidade de fazer negócios, pois são organizados por sócios ou pessoas indicadas pelos sócios com o intuito de comemorarem um acontecimento ou uma data importante. 
Brasília possui uma grande variedade de clubes, principalmente pelo fato de estar localizada em uma área castigada pela seca e longe do litoral e também por abrigar uma grande quantidade e variada categoria de servidores, tanto governamentais como privados. Um dos clubes mais requisitados da cidade é o late Clube de Brasília.

\section{1 - Panorama dos espaços para eventos disponíveis em Brasília}

Em sua entrevista, Lilia Tanner afirma que os profissionais do setor em Brasília estão consciente de que devem ser feitos investimentos neste tipo de infraestrutura na capital, no entanto a cidade já dispõe de vários espaços, onde diversos eventos são realizados. São eles:

\section{- ACADEMIA DE TÊNIS RESORT}

De acordo com seu "site" na "internet", a Academia de Tênis Resort dispõe de uma área gigantesca para eventos, onde está localizado o Americel Hall, atualmente o maior local para eventos em Brasília, com capacidade para receber 2500 pessoas sentadas. Este é dividido em 2 pavimentos, um dos quais para exposição e o outro com 5 salas para eventos; 4 camarotes; sala vip; 2 "foyers"; 2 camarins e plenário (central e pista). Além deste espaço, possui ainda o Park Fair para feiras, com dimensão de $7.200 \mathrm{~m} 2$ e capacidade para 8.000 pessoas; o salão Havana, que pode ser dividido em 5 subsalas; salão Murano; Salão Palace; Salão Branco; Salão Bugatti e o Hall Bugatti.

- PARLAMUNDI

O Parlamento Mundial da Fraternidade Ecumênica, o ParlaMundi da LBV, informa em seu "site" que foi idealizado e construído pelo Presidente Mundial da Legião da Boa Vontade, José de Paiva Netto, inaugurado em 25 de Dezembro de 1994, faz parte do conjunto arquitetônico do Templo da Boa Vontade em Brasília. 
O Salão Nobre é um espaço cultural destinado à realização de coquetéis, lançamentos literários, exposições e recepções em geral.

Possui uma estrutura com 5 pavimentos de mais de $6.000 \mathrm{~m}^{2}$ de área construída. Dispõe ainda de Ateliê de Arte, jardins internos, hall social e ala administrativa. 0 auditório Austregésilo de Athayde dispõe de 200 lugares e dos mesmos recursos do Plenário. Também oferece como opção um terceiro ambiente, o Auditório Tom Jobim, com capacidade para 100 pessoas e, ainda serviço de "buffet", equipamentos audiovisuais e estacionamento, além de salas de apoio e para "workshops".

O Plenário José de Paiva Neto possui capacidade para 500 pessoas sentadas, vista panorâmica da cidade de Brasília, oito cabines de tradução simultânea, salas para imprensa e os mais modernos recursos para a apresentação de conferências.

\section{- CENTRO DE EVENTOS DO HOTEL BLUE TREE}

Consta em seu "site" que o prédio do Blue Tree Towers Brasília oferece duas salas de reuniões para até 40 pessoas cada e uma sala para até 80 pessoas. 0 hotel oferece também "workstation" - bancada com quatro estações de trabalho equipadas com microcomputador, fax, copiadora, além de atendimento secretarial.

O Palácio de Eventos do Complexo Alvorada é uma área de $7.074 \mathrm{~m}^{2}$ que permite a realização dos mais variados eventos com entrada exclusiva e várias facilidades:

- "Internet" de alta velocidade.

- Estacionamento para 750 automóveis.

- "Workstation".

- Aluguel de equipamentos.

- Salas de apoio.

- "Staff" bilíngüe e especializado para acompanhar os eventos.

- Blue Tree Convention Center: 
Área de $1.100 \mathrm{~m}^{2}$, com $4 \mathrm{~m}$ de pé-direito, 14 salas com divisórias removíveis, capacidade para até 950 pessoas, "foyer" e área de exposição de $1.415 \mathrm{~m}^{2}$.

- Blue Tree Stars Halll:

É um salão de festas e eventos, com $7 \mathrm{~m}$ de pé-direito e área de $1.356 \mathrm{~m}^{2}$, com capacidade para até 1.200 pessoas, com divisórias removíveis e "foyer" de $468 m^{2}$.

- Blue Tree Theater:

Área de $540 \mathrm{~m}^{2}$, capacidade para 420 pessoas, 4 camarins e cabines para projeção e tradução simultânea.

Os serviços de apoio fazem do Complexo Alvorada o lugar ideal para a realização de eventos e convenções de qualquer porte. Pode-se contratar desde o café da manhã, "brunch", almoços, até jantares temáticos e coquetéis. Cada etapa do processo de organização é coordenada por uma equipe especializada para garantir o sucesso do evento.

Um exemplo de evento de grande porte que foi organizado neste hotel é a $1^{\text {a }}$ edição da UBRAFE 2003 - Congresso Brasileiro de Promoção Comercial e Feira Internacional de Promoção Comercial. Seu tema foi "Um modelo de promoção comercial para o Brasil", com o apoio institucional de vários ministérios, do SEBRAE - Serviço Brasileiro de Apoio ao Pequeno Empresário e da EMBRATUR - Instituto Brasileiro de Turismo. Ele se deu no período de 7 a 9 de maio, na forma de feira e congresso.

\section{- HOTEL NAOUM PLAZA}

Em seu folheto promocional, consta que este hotel possui uma excelente infraestrutura para eventos, disponibilizando desde Salas Executivas para até vinte pessoas, a um Centro de Convenções para 700 pessoas.

O Centro de Convenções Naoum Plaza possui uma área total de $348 \mathrm{~m}^{2}$ e capacidade de 180 a 700 participantes. É dotado de modernas divisórias que permitem a rápida distribuição do espaço conforme a necessidade do evento. 
Possui ainda o salão Palm Springs com uma área de $158 \mathrm{~m}^{2}$ e capacidade para 40 a 240 participantes; o salão Califórnia que dispõe de uma área de $126 \mathrm{~m}^{2}$ e sua capacidade vai de 30 a 180 participantes e o salão New Orleans com uma área de $64 \mathrm{~m}^{2}$ com capacidade para 45 a 60 participantes. O hotel ainda disponibiliza mais 6 Salas Executivas com áreas que vão de $20 \mathrm{~m}^{2}$ a $50 \mathrm{~m}^{2}$ e capacidade para 10 a 20 participantes cada uma.

\section{- CENTRO DE CONVENÇÕES ULISSES GUIMARÃES}

Em entrevista, o Engenheiro Eduardo Borges, responsável pela reforma do local, afirma que, atualmente, este espaço passa por uma grande reforma e a previsão para ser entregue é final do ano de 2004. O plano desenvolvido para esta reforma fará com que ele se torne um dos maiores e mais bem estruturados centros de convenções do Brasil. O público e área total será de 9424 pessoas e 54405 m2 respectivamente, sendo que possuirá um centro de convenções com capacidade para 4254 pessoas e uma área de 14785 m2, além de outros auditórios com 1710 lugares e 9600 m2. Possuirá também um salão de exposições com 11760 m2, que comportará 275 estandes e 3000 pessoas. A Praça dos Namorados terá 11370 m2 e será uma praça de alimentação para 460 pessoas.

\section{- CENTRO DE CONVENÇÕES ISRAEL PINHEIRO}

Em seu encarte, o Centro de Convenções Israel Pinheiro (CCIP) informa que é mantido pela Inspetoria São João Bosco, uma sociedade civil sem fins lucrativos, filantrópica, de assistência social e beneficência, de caráter educativo e social, que tem por fim a educação e a formação dos jovens, particularmente os mais necessitados.

Está localizado no Lago Sul, ao lado da Ermida Dom Bosco, possui uma área de 300 mil metros quadrados, cercados de verde e muita tranqüilidade, que garantem totais condições para o trabalho e lazer. Além disso, conta com um serviço próprio de "buffet" e recepção e, ainda, 54 apartamentos duplos para hospedagem, com televisão em cores, telefone, ventilador e varanda com vista panorâmica para o Lago Paranoá. 
Setor A

- auditório com 300 lugares

- plenário com 70 lugares

- 5 salas de reunião com 25 lugares cada uma

- "hall" com 400 m2 de área aberta

- restaurante com 120 lugares

- sala de acesso à internet

- secretaria com telefone e armários

- $\quad$ sala de administração de eventos

- capela com 100 lugares

- 54 apartamentos duplos

\section{Setor B}

- auditório com 200 lugares

- plenário com 60 lugares

- 4 salas de reunião com 40 lugares cada

- hall com 430 m2 de área coberta

- restaurante com 300 lugares

- secretaria com 3 cabines telefônicas

- sala de apoio anexa ao plenário

- capela com 50 m2

\section{- PAVILHÃO DE EXPOSIÇÕES DO PARQUE DA CIDADE}

Segundo Renato Montserrat, atual responsável pela locação do local, o Pavilhão de Exposições de Brasília possui uma área de 55.000 m2, com capacidade para 100.000 pessoas simultaneamente. Possui ainda 33 "boxes" para os expositores, contendo depósito e banheiro e um anfiteatro para 1000 pessoas sentadas.

- UNIVERSIDADE DE BRASÍLIA

Através de contato telefônico com Adalva Alcoforado, do setor de eventos da UnB - Universidade de Brasília, obteve-se a informação que ela é detentora de uma boa estrutura para eventos, a qual é largamente utilizada pela própria universidade, por outras entidades e até por embaixadas. Sua estrutura é dotada de 17 anfiteatros, cujas capacidades variam de 99 a 247 lugares e se localizam 
nas diferentes faculdades da universidade. Dispõe, ainda de um Centro Comunitário, onde são organizados as formaturas, colações de grau e outros eventos externos, com 2068 m2 e capacidade para 2500 pessoas sentadas ou 5000 em pé. A sala de cinema Dois Candangos também faz parte desta estrutura e sua capacidade é de 197 lugares.

Em sua entrevista, Lilia Tanner afirma que a infra-estrutura disponível atualmente em Brasília dificulta o trabalho de captação de eventos, pois os de grande porte que poderiam estar sendo realizados na cidade, acabam sendo realizados em outras, inclusive Goiânia, cuja localização é quase a mesma, mas o prestígio não se compara ao da capital. Esse cenário vem mostrar as dificuldades no que tange a infra-estrutura, que a cidade, no caso representada pelo BCVB, vem tendo na captação dos eventos de grande porte. Esse problema poderá ser sanado com o aperfeiçoamento da infra-estrutura para eventos, que se tornará condizente com a demanda e com os objetivos que se tem para a cidade. 


\section{CONCLUSÃo}

Segundo Ansarah (2000: 77), para enfrentar a competitividade do mercado internacional de eventos, o Brasil se viu obrigado a criar uma eficiente infraestrutura, disseminar informações didáticas e a fornecer treinamentos adequados, que permitam a profissionalização do setor e a melhoria da qualificação do profissional.

Os dados a seguir demonstram o potencial que Brasília dispõe, mesmo com a precariedade da situação: é a 9a cidade que mais capta eventos no Brasil, sendo que a maioria deles é da área profissional, principalmente médica. Dos participantes de eventos no país, Brasília atrai a parcela de $17 \%$ deles. A atividade de eventos representa 3.1\% do PIB na economia da cidade. Mesmo com toda dificuldade e amadorismo que Brasília apresenta no cenário atual, esses números já significam uma grande participação, só perdendo para as principais capitais do Brasil.

Em entrevista no dia 12 de setembro de 2003, a Gerente de Captação de Recursos e Mantenedores do Brasília Conevention \& Visitors Bureau, Lilia Tanner, afirmou que os maiores desafios do BCVB são a captação de recursos suficientes para a promoção necessária para Brasília despontar, até porque o CVB é incapaz de controlar o montante real arrecadado através da cobrança do "room tax"; o lançamento da cidade como produto para pacotes turísticos; o término da reforma do Centro de Convenções Ulysses Guimarães e a otimização da estrutura de lazer e entretenimento da cidade. Acrescentou ainda que "falta know how e que Brasília é desacreditada, embora seja a maior renda per capta do país", pelo fato de o trabalho que muitos profissionais fazem ser improvisado. A vinda de eventos internacionais é dificultada pelo fato de a cidade não dispor de vôos internacionais diretos para o aeroporto internacional de Brasília; de não possuir estrutura em termos de recursos financeiros para a captação destes eventos e de o BCVB não ser filiado ao ICCA, que é a detentora do banco de dados de eventos internacionais de grande porte. 
Lília Tanner (BCVB) complementou ainda que, com a reforma do Centro de Convenções Ulysses Guimarães e com a construção do Centro de Convenções do Hotel Meliá, cuja capacidade será para 3500 pessoas, Brasília passará a competir com as grandes capitais, tais como São Paulo, Rio de Janeiro e Belo Horizonte que, além de já terem superado os desafios que Brasília vem passando, oferecem diversas condições para que os eventos sejam realizados em sua cidade com o apoio por parte dos empresários, que oferecem cortesias ou descontos significativos, o que torna a localidade-sede mais atraente; com o governo fazendo a sua parte, liberando, por muitas vezes, taxas e impostos que, ao serem dispensados viabilizam o evento, tornado-o mais barato; imprimem mais importância e atenção ao evento, pois sabem que a permanência dos turista possibilita o crescimento econômico do local.

Tudo isso somado à participação e empenho de todos, principalmente dos CVBs locais, que atuam fortemente em prol das cidades em que se encontram, é algo que necessita ser passado ao BCVB, para que este possa atuar cada vez mais efetiva e eficazmente na captação de eventos para Brasília.

Com o crescimento que a atividade vem apresentando tanto em âmbito internacional como nacional, pode-se concluir que devem ser feitos investimentos na área de eventos, a qual tende a crescer cada vez mais. O fato de Brasília possuir uma ótima localização, no centro do país e da América Latina, é algo que facilita consideravelmente o acesso das pessoas e que deve ser explorado. 


\section{9 . BIBLIOGRAFIA}

Academia de Tênis Resort, disponível em: < http://www.atr_df.com.br >, acesso em: 30 de julho de 2003.

ANSARAH, Marília Gomes dos Reis. Turismo: Segmentação de mercado. São Paulo: Futura,2000.

Brasília Convention \& Visitors Bureau, disponível em: < http://www.brasiliaconvention.com.br >, acesso em: 13 de setembro de 2003.

BUENDÍA, Juan Manuel. Organización de reuniones: Convenciones, Congressos, Seminários. México: Trillas, 1991.

BCVB, folheto promocional.

CCIP, folheto promocional.

CANTON, Marisa. Turismo: Visão e ação. São Paulo: 1998.

Centro de Convenções Israel Pinheiro, disponível em: < http://www.ccip.com.br >, acesso em: 30 de julho de 2003.

CESCA, Cleuza Gimenes. Organização de eventos: manual para planejamento e execução. São Paulo: Summus,1997.

Federação Brasileira de Convention \& Visitors Bureau, disponível em : < www.fbcvb.com.br >, acesso em 21 de novembro de 2003.

Hotel Blue Tree Park, disponível em: < http://www.parkbrasilia.com.br >, acesso em: 30 de julho de 2003. 
Instituto Brasileiro de Turismo, disponível em: < http://www.embratur.gov.br >, acesso em 16 de setembro de 2003.

MATIAS, Marlene. Organização de eventos: procedimentos e técnicas. Barueri: Manole Ltda, 2001.

Naoum Plaza Hotel, folheto promocional.

NICHOLS, Barbara. Gerenciamento Profissional de eventos. Fortaleza: ABC, 1993.

PALLADINO, Rita. Revista dos Eventos: Clipping: Investimentos para sediar os Pan-Americanos. São Paulo, Outubro, 2002.

Parlamundi, disponível em: < http://www.tbv.com.br >, acesso em: 30 de julho de 2003.

Revista dos Eventos, disponível em: < http://www.revistadoseventos.com.br >, acesso em: 15 de setembro de 2003.

SARAIVA, Ana Lúcia Olegário. Planejamento e Organização de Eventos, disponível em: < http://www.turismounaerp.hpg.ig.com.br >, acesso em 15 de setembro de 2003.

TONATIUH, Cravioto Magallón. Organización de Congressos y Convenciones. México: Trillas, 1991.

VELLASCO, Ana Maria de Moraes Sarmento. Manual de orientações para a produção de textos acadêmicos. Brasília: UnB, 2003.

UBRAFE, folheto promocional 
